\title{
Konsekwencje nieleczonej lub źle leczonej astmy u dzieci
}

\section{Consequences of untreated or poorly treated asthma in children}

\author{
dr hab. n. med. Adam J. Sybilski, prof. CMKP \\ II Klinika Pediatrii, Centrum Medyczne Kształcenia Podyplomowego CMKP w Warszawie \\ Kierownik: dr hab. n. med. Adam J. Sybilski, prof. CMKP
}

Klinika Chorób Dziecięcych i Noworodkowych, Centralny Szpital Kliniczny Ministerstwa Spraw Wewnętrznych

i Administracji w Warszawie

Kierownik: dr hab. n. med. Adam J. Sybilski, prof. CMKP

\begin{abstract}
Streszczenie:
Astma jest najczęstszą przewlekłą chorobą dolnych dróg oddechowych u dzieci. Zwykle rozpoczyna się we wczesnym dzieciństwie, ma niestabilny i nieprzewidywalny przebieg. Zarówno przyczyny, jak i prawdopodobne mechanizmy patologiczne przeplatają się wzajemnie. U podłoża astmy leży proces zapalny w drogach oddechowych, w którego wyniku występują skurcz mięśniówki oskrzeli, pogrubienie ściany dróg oddechowych oraz wzmożone wydzielanie śluzu. Do czynników wpływających na złą kontrolę astmy, częste zaostrzenia zaliczamy: błędne rozpoznanie, nieprzestrzeganie zaleceń lekarskich, złą technikę podawania leków, niedostosowanie sprzętu do wieku dziecka, złą dawkę leku wziewnego, narażenie na czynniki drażniące i nasilające chorobę oraz brak leczenia wspótistniejącego nieżytu nosa. Konsekwencjami nieleczonej lub źle leczonej astmy u dzieci są: remodeling, upośledzenie rozwoju płuc, zwiększone ryzyko chorób płuc u dorosłych, częste zaostrzenia i infekcje dróg oddechowych, zahamowanie tempa wzrastania, otyłość, ograniczenie wydolności oddechowej i aktywności fizycznej, zaburzenia snu, obniżona jakość życia, absencja w szkole i gorsze wyniki w nauce oraz problemy psychiczne. Aby uniknąć niekorzystnych konsekwencji astmy u dzieci, należy wcześnie rozpoznać chorobę i prawidłowo ją leczzć, stosować odpowiednie, bezpieczne leki i techniki podawania, kontrolować i weryfikować postępowanie terapeutyczne, unikać czynników drażniących i nasilających objawy, edukować opiekunów i pacjentów, zachęcać do aktywności fizycznej, uprawiania sportów oraz redukcji masy ciała dzieci otyłych.
\end{abstract}

\begin{abstract}
:
Asthma is the most common chronic disease of the lower respiratory tract in children. It usually begins in early childhood and has an unstable and unpredictable course. The causes and probable pathological mechanisms are intertwined. The pathomechanism of asthma is an inflammatory process in the airways, resulting in bronchial muscular contraction, thickening of the airway wall, and increased secretion of mucus. Factors influencing poor asthma control, frequent exacerbations include misdiagnosis, non-compliance, poor medication administration technique, equipment disturbance to the child's age, wrong dose of inhalation drug, exposure to irritating factors and exacerbating the disease, and no treatment for concomitant allergic rhinitis. The consequences of untreated or poorly treated asthma in children are remodeling, impaired lung development, increased risk of lung diseases in adults, frequent exacerbations and infections of the respiratory tract, inhibition of growth, obesity, reduced respiratory efficiency and physical activity, sleep disorders, reduced quality of life, school absenteeism and lower school performance, and mental problems. To avoid the adverse consequences of asthma in children, it is necessary to: early recognize the disease and treat it properly, use appropriate, safe drugs and administration techniques, control and verify therapeutic management, avoid irritating factors, and aggravate symptoms, educate caregivers and patients, encourage physical activity, exercise sports and weight reduction of obese children.
\end{abstract}

Słowa kluczowe: astma, dzieci, zła kontrola, konsekwencje, leczenie

Key words: asthma, children, poor control, consequences, treatment 


\section{Wstęp}

Astma jest uznawana za najczęstszą przewlekłą chorobę dolnych dróg oddechowych u dzieci (występuje u 2-20\% populacji dziecięcej). Badania ECAP wykazały, że w populacji dziecięcej na tę chorobę cierpi 5-10\% [1]. Szacuje się, że obecnie w Polsce w grupie 1-5 lat może mieć astmę 100 tys. -150 tys. dzieci w każdym roczniku. Epizody obturacji drzewa oskrzelowego występowały przynajmniej raz u ok. $30 \%$ dzieci do 3. r.ż. i prawie u 50\% dzieci do końca wieku szkolnego. Tak więc astma u dzieci to problem nie tylko medyczny, ale również społeczny. Astma zwykle rozpoczyna się we wczesnym dzieciństwie, ma niestabilny i nieprzewidywalny przebieg, co stanowi wyjątkowe wyzwanie diagnostyczne i terapeutyczne. To choroba heterogenna, zatem zróżnicowanie jej przebiegów i postaci wynika $z$ tego, że ma ona wiele przyczyn oraz że w każdym pojedynczym przypadku ich rola jest różna. Dodatkowo przyczyny i prawdopodobne mechanizmy patologiczne przeplatają się wzajemnie, dlatego często trudno stwierdzić, które $\mathrm{z}$ nich były pierwsze, a które stały się ich następstwem [2].

Astma ma bardzo zróżnicowaną historię naturalną. Niekiedy dziecko doświadcza tylko kilku napadów, choć najczęściej objawy mają przebieg przewlekły i nawracający, nawet przez całe życie. Okresy bezobjawowe występują naprzemiennie $\mathrm{z}$ okresami zaostrzeń, po okresie poprawy następuje progresja choroby, czasem choroba kończy się śmiercią [3].

\section{Dlaczego astma nadal stanowi problem?}

U podłoża astmy leży proces zapalny w drogach oddechowych, w którego wyniku występują skurcz mięśniówki oskrzeli, pogrubienie ściany dróg oddechowych oraz wzmożone wydzielanie śluzu. Objawy, takie jak: świszczący oddech, duszność, ucisk w klatce piersiowej i kaszel, zmieniają się w czasie w zależności od stopnia ograniczenia wydechowego przepływu powietrza. Skutki astmy wpływają na życie pacjentów, ograniczając ich aktywność życiową, zawodową, a także zmniejszając komfort życia. Mogą również prowadzić do ciężkich zaostrzeń i nagłych zgonów.

Trzeba jasno powiedzieć, że pomimo doskonałych leków umożliwiających kontrolę choroby (wziewnych glikokortykosteroidów [wGKS], $\beta_{2}$-mimetyków, leków antyleukotrienowych), wypracowanych i ogólnie znanych standardów postępowania astma u dzieci nadal stanowi problem. Astma zakończona śmiercią dziecka jest na szczęście rzadka (waha się od 0,0 do $0,7 / 100000 \mathrm{w}$ różnych częściach świata), ale większości przypadków można prawdopodobnie zapobiec [4, 5]. Do czynników wpływających na złą kontrolę astmy i częste jej zaostrzenia, a nawet czasami powodujących zgon należą:

- błędne rozpoznanie

- nieprzestrzeganie zaleceń lekarskich przez pacjentów (compliance) - zwłaszcza u młodzieży

- zła technika podawania leków wziewnych

- niedostosowanie sprzętu do wieku dziecka (zła komora inhalacyjna, maseczka vs ustnik)

- zła dawka leku wziewnego

- narażenie na czynniki drażniące i nasilające chorobę

- brak leczenia współistniejącego nieżytu nosa [6, 7].

Obawy przed przedwczesnym rozpoznaniem astmy sprawiają, że dopiero częste występowanie klasycznych symptomów skłania do identyfikacji choroby. Pamiętajmy, że rozpoznanie astmy wczesnodziecięcej opiera się na wywiadzie i stwierdzeniu typowych objawów obturacji, dobrej odpowiedzi na właściwe leczenie i wykluczeniu innych przyczyn symptomów. Tylko wczesne rozpoznanie i wdrożenie prawidłowej terapii mogą zapobiec powikłaniom astmy u dzieci [8].

\section{Konsekwencje nieleczonej lub źle leczonej astmy u dzieci}

Mimo ogromnego postępu, jaki dokonał się w ostatnich latach, dotyczącego poznania patomechanizmów astmy i wprowadzenia do terapii nowych leków, astma wciąż pozostaje nieuleczalna. Jeśli jednak jest właściwie leczona, zwykle ma przebieg łagodny, minimalnie wpływa na życie chorego, nie zakłóca życia rodzinnego, nie wpływa na pracę zawodową, nie jest przeciwwskazaniem do uprawiania sportu, nawet wyczynowego. Źle kontrolowana astma w znacznym stopniu upośledza jakość życia, angażuje całą rodzinę, upośledza aktywność społeczną i szkolną dzieci. Niekontrolowana jest przyczyną spadku wydajności w nauce, częstej absencji chorobowej i dość częstej, w przypadku ciężkiej astmy oskrzelowej, hospitalizacji.

\section{Remodeling, upośledzenie rozwoju płuc, zwiększone ryzyko chorób płuc u dorosłych}

Podobnie jak u dorosłych u dzieci z astmą obserwujemy remodeling i eozynofilowe zapalenie dróg oddechowych. Niekorzystne przekształcenia strukturalne charakteryzują się uszkodzeniem nabłonka, pogrubieniem siateczkowej błony podstawnej (RBM, reticular basement membrane), przerostem i hiperplazją mięśni gładkich dróg oddechowych oraz angiogenezą [9]. Wzrost grubości RBM i eozynofilowy stan 
zapalny można zaobserwować już u przedszkolaków ze świszczącym oddechem (średnio w 29. miesiącu życia). Remodeling dotyczy zmian strukturalnych dużych i małych dróg oddechowych charakteryzujących się trwałym ograniczeniem przepływu powietrza [10]. U dzieci chorych na astmę, która była źle kontrolowana, stwierdzono obniżenie średnich wartości parametrów czynnościowych płuc $\left(\mathrm{FEV}_{1}\right.$, i $\left.\mathrm{FEV}_{1} \% \mathrm{FVC}\right) \mathrm{w}$ porównaniu z dziećmi niechorującymi na astmę [11]. 50-letnia obserwacja ponad 2,5 tys. osób (od 10.-15. r.ż. do 60.-65. r.ż.) wykazała, że astma i nawracające świsty (jako konsekwencja źle leczonej astmy) były czynnikiem ryzyka rozwoju przewlekłej obturacyjnej choroby płuc (POChP) oraz obniżenia FEV w $_{\text {w }}$ 5. dekadzie życia [12]. Niedawno opublikowana metaanaliza sugeruje, że świszczący oddech $\mathrm{w}$ dzieciństwie może powodować trwałe pogorszenie czynności płuc, które obejmuje dorosłe życie, a także zwiększone ryzyko wystąpienia POChP, zwłaszcza gdy towarzyszy jej atopia [13].

\section{Częste zaostrzenia i infekcje dróg oddechowych}

Zaostrzenie astmy to ostre pogorszenie kontroli objawów, nasilenie duszności, niepokoju dziecka, które mogą bezpośrednio zagrażać jego życiu. Częste zaostrzenia astmy są dowodem na ciężkość choroby oraz jej złe kontrolowanie. W postępowaniu z dzieckiem cierpiącym na astmę należy dążyć do zminimalizowania zaostrzeń, a w konsekwencji progresji choroby i zmian strukturalnych dróg oddechowych [14]. Wiele badań i metaanaliz jasno wskazuje na ścisłe powiązanie pomiędzy infekcjami dróg oddechowych (wirusowymi i bakteryjnymi) a astmą. Zwłaszcza infekcje rinowirusowe, mykoplazmatyczne mogą powodować zaostrzenia astmy u dzieci $[15,16]$. Jednocześnie - rozpoznana astma wczesnodziecięca, która nie jest niedostatecznie kontrolowana, sprzyja zakażeniom. Większa liczba zgłoszonych infekcji dróg oddechowych wiąże się z niższym poziomem kontroli astmy i odwrotnie - złe leczenie astmy powoduje częstsze infekcje [17].

\section{Zahamowanie tempa wzrastania}

Astma, podobnie jak inne choroby przewlekłe, może prowadzić, przez pogorszenie ogólnego stanu zdrowia, do upośledzenia rozwoju fizycznego. Tempo wzrastania dzieci z dobrze kontrolowaną astmą jest na ogół prawidłowe. Wskaźnik odchylenia standardowego przyrostu wysokości koreluje z czynnością płuc. Krzywe wzrastania najbardziej odbiegaja od prawidłowych, gdy choroba nie jest kontrolowana (jest źle leczona). Zahamowanie tempa wzrostu obserwuje się na ogół pod koniec 1. dekady życia i trwa ono do połowy wieku młodzieńczego. Warte podkreślenia jest to, że supresyjny wpływ stopnia ciężkości astmy, jej złego kontrolowania jest większy niż wpływ leczenia glikokortykosteroidami (GKS). Tak więc stopień kontroli objawów astmy ma większe znaczenie dla prawidłowego tempa wzrastania niż leczenie GKS [18, 19]. W badaniu Rotteveela i wsp. wykazano, że u dzieci w wieku 3-8 lat chorych na astmę znaczące zahamowanie tempa wzrastania było spowodowane niedostateczną kontrolą choroby podstawowej i raczej zbyt małą, a nie nadmierną dawką GKS [20].

\section{Otyłość}

Astma u dzieci wiąże się $\mathrm{z}$ nadwagą i otyłością. Badania dowodzą, że astma niekontrolowana lub źle leczona jest przyczyną otyłości u dzieci [21, 22]. Dzieci z nieleczoną astmą mają większy odsetek tkanki tłuszczowej i częściej cierpią na otyłość niż zdrowi rówieśnicy [23]. Nie jest dokładnie poznany mechanizm tej zależności, ponieważ styl życia dzieci z astmą (zmniejszona aktywność fizyczna, czas spędzany przed komputerem i telewizorem) nie wyjaśnia tego w pełni.

\section{Ograniczenie wydolności oddechowej i aktywności fizycznej}

Niekontrolowana astma jest związana z obniżoną sprawnością i brakiem intensywnej aktywności fizycznej w ciągu dnia. Dzieci z nadwagą, do czego predysponuje źle leczona astma, są mniej aktywne fizycznie niż dzieci o normalnej wadze [23-25]. Jednocześnie słabo kontrolowana astma wiąże się ze zmniejszoną wydolnością sercowo-naczyniową. Udowodniono również, że poprawa kontroli tej choroby jest związana z klinicznie istotnym wzrostem wydolności sercowo-naczyniowej oraz ze zwiększeniem codziennej aktywności fizycznej [26]. W porównaniu z dziećmi z łagodniejszymi objawami astmy, dzieci z bardzo słabo kontrolowanymi objawami doświadczały większych ograniczeń na zajęciach gimnastycznych, podczas uprawiania sportu i intensywnych ćwiczeń, ale również podczas łagodnych zajęć [27].

\section{Zaburzenia snu}

Od początku lat 90. ubiegłego wieku przeprowadzono wiele badań wskazujących na ogromny wpływ astmy, zwłaszcza źle kontrolowanej lub nieleczonej. Zaburzenia snu u dzieci z astmą opisywano jako senność i zmęczenie w ciągu dnia, trudności w utrzymaniu snu oraz budzenie się wcześnie rano. Autorzy zalecają przeprowadzanie badań przesiewowych u dzieci z astmą pod kątem zaburzeń snu [28]. Badania pokazują, że ponad połowa dzieci oraz młodzieży ma symptomy nocne astmy, stanowiące konsekwencję 
niedostatecznego leczenia tej choroby, co w znacznym stopniu wpływa na sen oraz dzienne funkcjonowanie pacjentów [29, 30]. Jednocześnie w kolejnym badaniu stwierdzono, że przyjmowanie leków kontrolujących astmę zmniejsza objawy nocne i senność w ciągu dnia [31]. Stosowanie inhibitorów leukotrienów ma również pozytywny wpływ na problemy ze snem. Badacze sugerują, że pozytywny efekt działania tych leków może wynikać z wysokiego odsetka obturacyjnego bezdechu sennego i alergicznego nieżytu nosa u dzieci z astmą. Dobra kontrola astmy powodowała spadek senności w ciągu dnia [32].

\section{Obniżenie jakości życia}

W systematycznym przeglądzie piśmiennictwa stwierdzono istotny związek między nasileniem astmy a jakością życia dzieci. Podkreślono znaczenie oceny ciężkości tej choroby oraz znaczenie kontrolowania objawów [33]. Stwierdzono, że słaba kontrola tej choroby wiąże się z niską jakością życia, ze złą jakością snu i z sennością w ciągu dnia [34, 35]. Ostatnie badania autorów z Brazylii potwierdziły ogólnie znaną prawidłowość, że ciężka i umiarkowana astma, źle kontrolowana lub nieleczona wpływa na jakość życia dzieci [36].

\section{Absencja w szkole i gorsze wyniki w nauce}

Wyrazem manifestacji problemów zdrowotnych jest absencja w szkole. Dotyczy ona zwłaszcza zwolnień z zajęć WF-u. Niektóre badania wskazują, że nawet $1 / 4$ dzieci chorujących na astmę jest zwalniana $\mathrm{z}$ tych lekcji [37]. Zasadniczo astma wiąże się z absencją uczniów, czynnikiem ryzyka słabych wyników i porzucania nauki $[36,38]$. Dodatkowo powoduje absenteizm (obecność fizyczna na zajęciach przy równoczesnej nieobecność mentalnej) [38, 39]. Ocenia się, że absenteizm w większym stopniu wpływa na złe wyniki w nauce niż fizyczna nieobecność. To wszystko powoduje, iż wyniki, które osiągają uczniowie ze źle kontrolowaną astmą, są znacznie gorsze niż w przypadku dzieci zdrowych lub prawidłowo leczonych [36, 40]

\section{Problemy psychiczne}

Jest niewiele badań oceniających wpływ astmy, zwłaszcza w przypadku dzieci, na problemy psychiczne. Wiele tych badań jest niespójnych metodologicznie, a kryteria ocen są bardzo różne [41]. Niemniej jednak stwierdzono, że zwiększona częstość psychopatologii występuje u dzieci z ciężką astmą, ale istnieje niewiele dowodów sugerujących, że dotyczy to dzieci z łagodną astmą. Depresja i zaburzenia lękowe są częstsze u dzieci z ciężką astmą [42]. W ostatnio opublikowanym badaniu wykazano, że choroby psychiczne występowały u 72\% chorych na astmę, a tylko u 22\% osób z grupy kontrolnej. Najczęstszą zidentyfikowaną chorobą psychiczną było uogólnione zaburzenie lękowe (odpowiednio 32\% vs 13\%) [43].

\section{Podsumowanie}

Jak widać, astma źle leczona, niekontrolowana lub nierozpoznana może negatywnie wpływać na wiele aspektów życia chorego dziecka i jego rodziny. Jak można temu zaradzić? Aby uniknąć niekorzystnych konsekwencji astmy u dzieci, należy:

- wcześnie rozpoznać astmę i prawidłowo ją leczyć (według standardów postępowania)

- stosować odpowiednie, bezpieczne leki, techniki podawania (w zależności od wieku dziecka)

- kontrolować i weryfikować postępowanie terapeutyczne

- nie dopuszczać do epizodów zaostrzeń - unikać czynników drażniących i nasilających objawy (np. dymu tytoniowego, zanieczyszczeń powietrza)

- edukować opiekunów i pacjentów (stworzyć pisemny, indywidualny plan postępowania z chorobą, zawierający codzienne dawkowanie leków oraz dokładne wytyczne w celu wczesnej identyfikacji i postępowania w przypadku zaostrzeń lub utraty kontroli choroby)

- zachęcać do aktywności fizycznej, uprawiania sportów oraz redukcji masy ciała dzieci otyłych

- stosować działania profilaktyczne w celu uniknięcia braku kontroli astmy.

\section{Piśmiennictwo}

1. Samoliński B, Sybilski AJ, Raciborski F et al. Występowanie astmy oskrzelowej u dzieci, młodzieży i młodych dorostych w Polsce w świetle badania ECAP. Alerg Astma Immunol. 2009; 14(1): 27-34

2. Papadopoulos NG, Arakawa H, Carlsen KH et al. International consensus on (icon) pediatric asthma. Allergy. 2012; 67: 976-97.

3. Global Strategy for Asthma Management and Prevention (2020 update). https://ginasthma.org/reports (access: 16.12.2020)

4. Carroll W, Clayton S, Frost $S$ et al. If it's 'only' asthma, why are children still dying? Arch Dis Child. 2020; 105: 494-8.

5. Asher I, Pearce N. Global burden of asthma among children. Int J Tuberc Lung Dis. 2014; 18: 1269-78.

6. Herrera AM, Fitzgerald DA. Question 1: Why do children still die from asthma? Paediatr Respir Rev. 2018; 27: 40-3. 
7. Connett GJ, Connett LA, Thomas M. Determining the reasons for poorly controlled asthma in an adolescent. BMJ. 2019; 364: 175 .

8. Doniec Z, Mastalerz-Migas A, Bręborowicz A et al. ReKOMendacje Postepowania $w$ astmie wczesnodziecięcej dla lekarzy Podstawowej Opieki Zdrowotnej - KOMPAS POZ. Fam Med Prim Care Rev. 2016; 18(2): 181-219.

9. Malmström K, Lohi J, Sajantila A et al. Immunohistology and remodeling in fatal pediatric and adolescent asthma. Respir Res. 2017; 18: 94.

10. D'Amato G, Vitale C, Lanza M et al. Near fatal asthma: treatment and prevention. Eur Ann Allergy Clin Immunol. 2016; 48(4): 116-22.

11. Strunk RC, Weiss ST, Yates KP et al. Mild to moderate asthma affects lung growth in children and adolescents. J Allergy Clin Immunol. 2006; 118(5): 1040-7.

12. Tagiyeva $N$, Devereux $G$, Fielding $S$ et al. Outcomes of Childhood Asthma and Wheezy Bronchitis. A 50-Year Cohort Study. Am J Respir Crit Care Med. 2016; 193: 23-30.

13. Ma H, Yuanyuan Li Y, Tang L et al. Impact of childhood wheezing on lung function in adulthood: A meta-analysis. PLoS One. 2018; 13: e0192390.

14. Engelkes M, Janssens HM, de Ridder MA et al. Real life data on incidence and risk factors of severe asthma exacerbations in children in primary care. Respir Med. 2016; 119: 48-54.

15. Priante E, Cavicchiolo ME, Baraldi E. RSV infection and respiratory sequelae. Minerva Pediatr. 2018; 70: 623-33.

16. Kumar S, Roy RD, Sethi GR et al. Mycoplasma pneumoniae infection and asthma in children. Trop Doct. 2019; 49: 117-9.

17. Zomer-Kooijker K, Uiterwaal CS, Verschueren KJ et al. Respiratory tract infections and asthma control in children. Respir Med. 2014; 108: 1446-52.

18. McCowan C, Neville RG, Thomas GE et al. Effect of asthma and its treatment on growth: four year follow up of cohort of children from general practices in Tayside, Scotland. BMJ. 1998; 316: 668-72.

19. Zhang L, Prietsch SOM, Ducharme FM. Inhaled corticosteroids in children with persistent asthma: effects on growth. Cochrane Database Syst Rev. 2014; (7): CD009471.

20. Rotteveel J, Potkamp J, Holl H et al. Growth during early childhood in asthmatic children: relation to inhalation steroid dose and clinical severity score. Horm Res. 2003; 59(5): 234-8.

21. Lai L, Zhang T, Zeng Xet al. Association between Physician-Diagnosed Asthma and Weight Status among Chinese Children: The Roles of Lifestyle Factors Int J Environ Res Public Health. 2020; 17: 1599.

22. Lang JE, Holbrook JT, Wise RA et al; American Lung Association-Asthma Clinical Research Centers. Obesity in children with poorly controlled asthma: Sex differences. Pediatr Pulmonol. 2013; 48(9): 847-56.
23. Vahlkvist $S$, Pedersen $S$. Fitness, daily activity, and body composition in children with newly diagnosed, untreated asthma. Allergy. 2009; 64: 1649-55.

24. Lam KM, Yang YH, Wang CL et al. Physical Activity in School-Aged Children with Asthma in an Urban City of Taiwan. Pediatr Neonatol. 2016; 57(4): 333-7.

25. West SL, Banks L, Schneiderman JE et al. Physical activity for children with chronic disease; a narrative review and practical applications. BMC Pediatrics. 2019; 19: 12.

26. Vahlkvist $S$, Inman $M D$, Pedersen $S$. Effect of asthma treatment on fitness, daily activity and body composition in children with asthma. Allergy. 2010; 65: 1464-71.

27. Holderness H, Chin N, Ossip DJ et al. Physical Activity, Restrictions in Activity, and Body Mass Index among Urban Children with Persistent Asthma. Ann Allergy Asthma Immunol. 2017; 118: 433-8.

28. Banasiak NC. Understanding the Relationship Between Asthma and Sleep in the Pediatric Population. J Pediatr Health Care. 2016; 30(6): 546-50.

29. Fagnano M, Bayer AL, Isensee CA et al. Nocturnal asthma symptoms and poor sleep quality among urban school children with asthma. Acad Pediatr. 2011; 11(6): 493-9.

30. Mitchell DK, Kopel SJ, Williams B et al. The Association Between Asthma and Sleep in Urban Adolescents With Undiagnosed Asthma. J Sch Health. 2015; 85: 519-26.

31. Garrison MM, Lozano P, Christakis DA. Controller medication use and sleep problems in pediatric asthma. Arch Pediatr Adolesc Med. 2011; 165: 826-30.

32. Gerber L. Sleep deprivation in children: A growing public health concern. Nursing. 2014; 44: 51-4.

33. Everhart RS, Fiese BH. Asthma severity and child quality of life in pediatric asthma: A systematic review. Patient Educ Couns. 2009; 75: 162-8.

34. Li Z, Huang IC, Thompson L et al. The relationship between asthma control, daytime sleepiness, and quality of life among children with asthma: A path analysis. Sleep Med. 2013; 14: 641-7.

35. van Maanen A, Wijga AH, Gehring U et al. Sleep in children with asthma: Results of the PIAMA study. Eur Respir J. 2013; 41: 832-7.

36. Roncada $C$, de Souza $R G$, Costa $D$ et al. Pediatric asth$m a$ : impact of the disease in children receiving outpatient treatment in southern brazil. Rev Paul Pediatr. 2020; 38: e2018398.

37. Shohat T, Graif Y, Garty BZ et al. The child with asthma at school: results from a national asthma survey among schoolchildren in Israel. J Adolesc Health. 2005; 37: 275-80.

38. Johnson SB, Spin P, Connolly F et al. Asthma and Attendance in Urban Schools. Prev Chronic Dis. 2019; 16: E148.

39. Gottfried MA. Evaluating the relationship between student attendance and achievement in urban elementary and middle 
schools: an instrumental variables approach. Am Educ Res J. 2010; 47: 434-65.

40. Mizan SS, Shendell DG, Rhoads GG. Absence, extended absence, and repeat tardiness related to asthma status among elementary school children. J Asthma. 2011; 48: 228-34.

41. Opolski M, Wilson I. Asthma and depression: a pragmatic review of the literature and recommendations for future research. Clin Pract Epidemiol Ment Health. 2005; 1: 18.

42. Mrazek DA. Psychiatric complications of pediatric asthma. Ann Allergy. 1992; 69: 285-90.

43. Doğru H, Sürer-Adanır A, Özatalay E. Psychopathology, health-related quality-of-life and parental attitudes in pediatric asthma. J Asthma. 2019; 56: 1204-11.

\section{ORCID}

A.J. Sybilski - ID - http://orcid.org/0000-0003-2389-277X
Konflikt interesów/Conflict of interests:

Nie występuje.

Finansowanie/Financial support:

Nie występuje.

Etyka/Ethics:

Treści przedstawione w artykule są zgodne z zasadami Deklaracji Helsińskiej, dyrektywami EU oraz ujednoliconymi wymaganiami dla czasopism biomedycznych.

Copyright: @ Medical Education sp. z 0.0. This is an Open Access article distributed under the terms of the Attribution-NonCommercial 4.0 International (CC BY-NC 4.0). License (https://creativecommons.org/licenses/by-nc/4.0/), allowing third parties to copy and redistribute the material in any medium or format and to remix, transform, and build upon the material, provided the original work is properly cited and states its license.

Adres do korespondencji

dr hab. n. med. Adam J. Sybilski, prof. CMKP

II Klinika Pediatrii, Centrum Medyczne Kształcenia Podyplomowego CMKP w Warszawie

02-507 Warszawa, ul. Wołoska 137

e-mail: adam.sybilski@cskmswia.pl 